\title{
Happiness surveys: exclusive guides for policy?
}

\author{
Gunther Tichy* \\ Austrian Institute of Economic Research, Vienna, Austria
}

\begin{abstract}
Happiness is increasingly named as a target of policy measures. Apart from the confusing fact that the attention-grabbing catchword 'happiness' refers to 'life satisfaction' in most cases, this approach appears preferable to alternatives as utility functions, magic polygons or to the opaque decisions of politicians. A life-satisfaction-oriented policy would prove welfare-improving, focusing on fair distribution of income and wealth, social goals and institutional goals such as health, freedom and social capital. However, these advantages would come at a price: medium-term life satisfaction goals would clash with longer-term aspects resulting from behaviour which is not aimed at sustainability, yet has a direct impact on it. The second problem is that the respondents can misjudge the satisfaction resulting from their choices, and may not be aware of the (longer-term) consequences of their decisions. Furthermore, policy cannot control some of the central elements of life satisfaction, which means that citizens will sooner or later discover that policy cannot live up to its promise. 'Happiness' as a policy goal cannot relieve politicians from constantly assessing trade-offs and sustainability and searching for compromises among the conflicting ideological positions.
\end{abstract}

Keywords: happiness, life satisfaction, sustainable policy

JEL codes: $D 12, D 63, D 7, E 61$

\section{INTRODUCTION}

The goals of economic policy have been increasingly questioned in recent decades. In the 1960 s the so-called 'magic triangle', of full employment, price stability and growth, and the 'magic pentagon', which further included a balanced current account and income distribution, were theoretically accepted and to an extent realised. The label 'magic' indicated the awareness of serious trade-offs. Neoclassical ideas of yield-guided transactions in perfect financial markets subsequently eliminated balance of payments as a policy goal, and increased efficiency orientation eliminated distribution-related targets. Parallel to this shift, a separation emerged, with monetary policy pursuing price stability as the single goal, and governments focusing on employment, almost exclusively by means of growth; most recently, debt reduction has tended to dominate governments' policy. Monetary and fiscal policy were (and still are) seldom coordinated, and little attention was paid to trade-offs or the preferences of citizens. To further complicate matters, the goal of environmental sustainability was introduced by experts and concerned citizens, yet clearly ranked far behind price stability and employment in the policy agenda. A diffuse sense of unease

* Thanks are due to K. Aiginger, M. Schratzenstaller, two anonymous referees and the participants in the Feedback Conference of the project WWWforEurope at the Austrian Institute for Economic Research in Vienna (September 2013) for inspiring discussions and helpful comments on a companion paper.

Received 26 December 2013, accepted 15 May 2014 
towards economic policy and its goals has emerged, which was considerably aggravated during the financial crisis.

In this context, it is not surprising that citizens' 'happiness' has been increasingly discussed as a new, even exclusive, guide for economic policy. ${ }^{1}$ In theoretical terms, it is considered a superior guide to utility functions, which are based on rational behaviour and purely economic goals. In terms of real-world strategy formulation, citizens' preferences, as revealed by the determinants of 'happiness', are considered superior to the opaque decisions of politicians and the self-serving pressures of lobbies. However, this proposal is not unproblematic. The quest for 'happiness' has created a specific market (Flora 2009); in the striving for popularity, marketing-oriented terminology does not differentiate between Subjective Well-being, Life Satisfaction and Happiness, so that the term 'happiness' loses precision. This paper posits that the surveys are still adversely affected by problems of non-response, selection bias and seemingly objectiveness, and that the ambiguous goal of 'happiness' would tend to support a myopic policy, overemphasising short-term emotional aspects. A life-satisfaction-oriented policy could in fact improve medium-term orientation, but still fail to be sustainable by neglecting trade-offs and long-term aspects. Furthermore, a serious danger of self-defeat is inherent to this approach, as policy cannot control some of the decisive determinants of life satisfactions, so that a further decline in policy credibility is likely. Subjective well-being, defined properly, can be an important element in a vector of policy goals. But it cannot relieve politicians from constantly assessing trade-offs and sustainability.

\section{SUBJECTIVE WELL-BEING}

In contrast to psychologists and sociologists, who accurately differentiate between subjective well-being (SWB), happiness and life satisfaction, economists frequently interchange these terms. The World Happiness Report, for example, is fully aware of this differentiation, but nevertheless speaks systematically of 'happiness' whether it deals with life satisfaction or positive affect.

'Subjective well-being' is the general expression used to cover a range of individual self-reports of moods and life assessments. The word 'happiness' is often used in an equally general way, as in the title of this report. It does help to focus thinking, and attracts attention more quickly than does 'subjective well-being'. But there is a risk of confusion. A bit of advance explanation may help to keep things clear. ... How does happiness come into this classification? For better or worse, it enters in three ways. It is sometimes used as a current emotional report - 'How happy are you now?', sometimes as a remembered emotion, as in 'How happy were you yesterday?', and very often as a form of life evaluation, as in 'How happy are you with your life as a whole these days?' People answer these three types of happiness question differently, so it is important to keep track of what is being asked. The good news is that the answers differ in ways that suggest that people understand what they are being asked, and answer appropriately. Thus when people are asked about their happiness now or yesterday, the answers are closely correlated with current activities and events in their lives today or yesterday. By contrast, when people are asked how happy they are with their lives as a whole these days, their answers match very closely the answers to other similar evaluations of life as a whole. (Helliwell/Wang n.d.: 11, emphasis added)

1 'Increasing public happiness has become an overt goal of public policy in many countries, sometimes resting uneasily alongside more familiar goals such as economic growth, national security, and social justice' (Mulgan 2013: 517). 
In addition to cognitive (life satisfaction) and affective (happiness, anger, worry) elements of SWB focusing on a person's experiences, the psychological literature further distinguishes a state of eudaimonia or good psychological functioning (Clark/Senik 2011). This paper follows the psychology nomenclature: 'life satisfaction' as the super ordinate concept, while 'happiness' or 'positive affect' are restricted to the emotional aspects ('How happy are you now?' or 'How happy were you yesterday?'); for the cognitive aspects ('On the whole, are you very satisfied, fairly satisfied, not very satisfied or not at all satisfied with the life you lead?') the term 'life satisfaction' is used.

[B] oth kinds of happiness have predictable causes that reflect various facets of our human nature and our social life. Affective happiness captures the day-to-day joys of friendship, time with family, and sex, or the downsides of long work commutes and sessions with one's boss. Evaluative happiness measures very different dimensions of life, those that lead to overall satisfaction or frustration with one's place in society. Higher income, better health of mind and body, and a high degree of trust in one's community ('social capital') all contribute to high life satisfaction; poverty, ill health, and deep divisions in the community all contribute to low life satisfaction. (Sachs n.d: 6, emphasis added)

Life satisfaction therefore seems to be the better choice of a policy goal, but the consequences have not been worked out in detail. The following sections collect the determinants of life satisfaction and happiness elaborated by a broad literature and check their aptitude as a policy goal. ${ }^{2}$

\section{LIFE SATISFACTION AND ITS DETERMINANTS}

Reviewing the literature with a view to policy relevance, this paper will distinguish individual, economic, institutional and social determinants of life satisfaction. This separation points to the different potentialities of impact through (economic) policy or institutional change. Yet it is to some extent arbitrary, not exclusive, and the various determinants frequently influence each other, with income, for example, positively correlating with health.

Discussing the results, it is important to bear in mind that the surveys themselves do not ask for the determinants of life satisfaction; they only ask if the respondent is more or less satisfied with the life he leads. It is left to SWB research to discover these determinants by comparing the individual's degree of life satisfaction with the characteristics of the respondent (marital status, religion, income, etc.) and his economic and social environment. The estimation is restricted to orders of magnitude, however, for three reasons. First, only dichotomous variables, such as divorce or employment, can be defined clearly,

2 The studies dealing with SWB are based on a large number of surveys. The World Databank of Happiness comprises 4027 entries, of which two-thirds (Europe 70 per cent, USA 54 per cent) refer to global cognitive measures, representing the more reflective of enduring social conditions. The relevant questions concerning life satisfaction are similar in the different surveys. The European Social Survey poses two questions: 'Taking all things together, how happy would you say you are?' and 'All things considered, how satisfied are you with your life as a whole nowadays?', while the World Values Survey asks almost the same as the latter question, except that it uses 'these days' instead of 'nowadays', and Eurobarometer asks: 'On the whole, are you very satisfied, fairly satisfied, not very satisfied or not at all satisfied with the life you lead?' The three separate Cantril Ladder questions in the Gallup World Poll ask respondents to evaluate their lives 'at the present time', 'five years ago' and 'five years in the future' on a ten-rung ladder. Owing to the similarity of the questions, research has been able to discover very similar stories about the likely sources of a good life. 
while qualitative but equally important variables, such as health, distribution, trust or participation, are less easy to isolate. Second, many determinants are correlated, so that coefficients and causalities may be less reliable. And, finally, to compare the importance of determinants, they must be transformed into income equivalents, which is a hazy task to begin with, but all the more so when (the level of) income belongs to the less important determinants of life satisfaction.

\subsection{Individual determinants of life satisfaction}

Assessing life satisfaction as a policy goal it is important to keep in mind that individual determinants are more important than economic ones. Inglehart/Klingemann (2000: 165) stress the 'growing evidence that an individual's happiness level is largely shaped by genetic factors ... Neuroscientists have found close linkage between reported happiness and dopamine and serotonin levels in the brain'. Survey-based life-satisfaction studies concur that health and marital status are - together with unemployment - among the most important determinants of life satisfaction. Blanchflower/Oswald (2004: 12) found for the US and Great Britain that an existing (first) marriage contributes two-thirds more to life satisfaction than being employed. On an OECD-wide basis and roughly a decade later (data for 2009 and 2010), Boarini et al. (2012: 21) identified marriage as contributing only half as much as employment, but the effect is still the equivalent of a more than three-fold increase in income. The quality of the marriage, however, as well as that of social relations, turned out to be more important than the marriage itself or the sheer number of relations (Demir 2013: 817-818).

The satisfaction-heightening effect of health is rated most important by the respondents (Oswald 1997: 1827; Clark/Oswald 2002; Helliwell 2002; Boarini et al. 2012: 21). This information, however, is less reliable and less suited to quantification than other aspects for two main reasons: the responses appear to be almost identical to those about life satisfaction in general, ${ }^{3}$ and self-assessed health is only weakly correlated with actual (measured) health (Diener et al. 1999; Deaton 2008: 66). Furthermore, there is good evidence that some of the association between good health and high life satisfaction is due to high life satisfaction causing good health (Diener/Chan 2011). Serious illness or being disabled reduces life satisfaction considerably, but part of the loss wears off (Donovan et al. 2002: 24). Disabled people are less satisfied with their lives by $1 / 2 \mathrm{a}$ percentage point (severely disabled by 1 percentage point) on a seven-point scale, according to Oswald/Powdthavee (2005).

A less frequently considered but highly important determinant of life satisfaction is relational goods or 'the affective/expressive, non-instrumental, side of interpersonal relationships'. The Relational Time Index, comprising the elements 'attend social gatherings', 'attend cultural events', 'participate in sports', 'perform volunteer work' and 'attend church or religious events' is significantly correlated with satisfaction (Becchetti et al. 2007). In OECD countries, 'have friends to count on' and 'volunteering' respectively increase life satisfaction five and two-and-a-half times more than a doubling of (log) income (Boarini et al. 2012: 21). Persons trusting each other are in general more satisfied (Helliwell 2002: 13), as are introverted people relative to extroverted ones (Kasser/Ryan 2001). Other measures of social support and trust in others are also positively associated with life satisfaction (Helliwell/Wang 2011). Religion, such as belief in god and regular

3 A 1 per cent better assessment of own health is connected with a 1 per cent increase in life satisfaction (Helliwell 2002: 9). 
attendance of church, influences satisfaction positively (Diener et al. 1999; Helliwell 2002: 13), especially in bad times.

With respect to age, Blanchflower/Oswald (2004: 9) find a U-shaped relation. The trough lies between 45 and 55 years (Donovan et al. 2002: 14) or between 35 and 45 years in the international investigation by Helliwell (2002: 12), both of these studies reflecting the well-known midlife crisis.

Last but not least, gender aspects appear to have some influence on life satisfaction. Women are more satisfied with their lives than men in Great Britain and the US (Blanchflower/Oswald 2004), but not in Switzerland (Frey/Stutzer 2000: 925). Similarly to the US and Great Britain, Boarini et al. (2012) find that being female is associated with higher levels of life satisfaction in 34 OECD countries, but with lower levels of affect balance. Contrary to expectations, women's life satisfaction has declined in the US (Blanchflower/Oswald 2004: 6). As a rather curious addition, even images of beauty appear to be relevant for life satisfaction, with images of ideal beauty bolstering young women's satisfaction and images of body size boosting that of men (Argyle 1987).

\subsection{Institutional determinants}

Unlike individual determinants, institutional ones can in principal be shaped by policy, even if only through interventions in the system. Among the institutional determinants, the satisfaction-heightening effect of health indicates the importance of the country's health system. Self-determination, as realised in personal freedom, employee participation or participation in society, is a second fundamental contributor to life satisfaction. Veenhofen (2000) has demonstrated the positive influence of personal freedom on life satisfaction for a broad sample of countries, and Inglehart/Klingemann (2000: 171f) have described this dependence as S-shaped. ${ }^{4}$ Blinder (1990), Kruse/Blasi (1995) and OECD (1995) emphasise the positive influence of employee participation on life satisfaction. Frey/Stutzer (2000) point towards the satisfaction-increasing effects of political participation, with Swiss direct democracy serving as an example. The importance of participation in society has been worked out for the US by Putnam (2001), for Great Britain by Donovan et al. (2002: 26), and by Helliwell (2002: 13) for a large number of quite different states, with membership in clubs, tax compliance and trust showing a markedly positive contribution to life satisfaction. Putnam (2001) and Bjørnskov (2003) have emphasised the general contribution of Social Capital to life satisfaction.

The influence of education on life satisfaction is contested: Boarini et al. (2012) found a significant positive effect, especially for tertiary education, in 34 OECD countries. Blanchflower/Oswald (2004: 11) detected a small positive effect in their earlier study for the US and Great Britain; however, Diener et al. (1999), Helliwell (2002: 11) and Kahneman/Deaton (2010) found no effect exceeding the difference in income. Education, nevertheless, may have some non-income benefits for individuals who get an education, especially in poor countries. Yet this appears smaller than is often claimed by educationalists, reflecting the well-known gap between individual and social returns. On top of this, important social effects may occur through an informed electorate or through reduced birth rates, better health and reduced mortality in poor countries (Layard et al. n.d.: 78).

4 For the descendents of former Russia, the increase in personal freedom did not contribute much to life satisfaction; it was considerably higher in the less suppressed Eastern European countries and Latin America. In Western democracies, the effect of a further increase in personal freedom on life satisfaction is again small. 


\subsection{Economic determinants of life satisfaction}

Unemployment influences life satisfaction (negatively) more than any other economic determinant. 40 per cent of Europe's unemployed are not at all satisfied, compared to 19 per cent of the total population (Alesina et al. 2001a: table 2.2). The average American unemployed person attains only 54 per cent of the total population's satisfaction (Di Tella et al. 2006: 811). Boarini et al. (2012: 21) estimates for OECD countries that 'not being unemployed and not having health problems are associated with a change in life satisfaction roughly equivalent to an eight-fold increase in income'. Life-satisfaction studies distinguish carefully between the effects of unemployment per se on life satisfaction and the resulting loss of income. ${ }^{5}$ The isolated pure unemployment effect, the psychological sequel, corresponds to a plunge from the top income quartile to the lowest one (Di Tella et al. 2006: 812). The bulk of evidence shows that even low-quality jobs are associated with higher life satisfaction than unemployment, and this effect remains statistically significant for most specifications of 'bad' jobs. Even concerns about potential job loss considerably reduce life satisfaction (Uhde 2010: 425). Life satisfaction increases substantially when people go from being completely out of work to joining the German workfare program (Wulfgramm 2011). The loss of income resulting from the loss of a job, whose size depends on the replacement ratio, must be added to the psychological loss of satisfaction, but this effect is considerably smaller.

Due to the strong psychological effect, men of working age suffer most from unemployment (Blanchflower/Oswald 2004: 13) and women over 50 the least (Gerlach/Stephan 1996: 326). The impact, however, levels off gradually due to the 'adaptation effect' (Clark/Oswald 1994), but the previous level of satisfaction is never attained, even in subsequent employment (Lucas et al. 2004). A 'relativity effect' reduces the psychological consequences when marriage partners or friends are also unemployed, when the local unemployment rate is high, or when the unemployed person can rate his unemployment as 'normal' or 'undeserved' (Clark 2001). As Section 3.4 will show, a high unemployment rate not only reduces the life satisfaction of the unemployed, but also that of employed persons (Clark et al. 2008b).

Leisure contributes to life satisfaction, even in the US (Donovan et al. 2002: 25f). This is astonishing, as US-Americans work considerably longer hours than Europeans, naming this as an explanation for their superior economic performance and explaining it as a deliberate reaction to lower taxation (Prescott 2004). Life satisfaction research, however, suggests that US-Americans' long working hours are not deliberately chosen. In 1955, 49 per cent indicated that they would prefer to have more leisure, and in 1991 this share had risen to 68 per cent (Donovan et al. 2002: 25). Alesina et al. (2001b; 2006) demonstrated that it is beyond the power of the individual employee to reduce his working time; only collective action by labour unions can achieve this. Kahneman/Krueger (2006) as well as Frey/Stutzer (2008) emphasise the negative influence of commuting time.

The effect of the income level on life satisfaction is complex. Persons with higher income are more satisfied. 87 per cent of respondents in the top income quartile consider themselves highly or fairly satisfied, compared to only 73 per cent in the lowest quartile (Di Tella et al. 2006: 811). In Boarini et al.'s (2012) study of the 34 OECD countries, (log) household income is highly significant, with a doubling of income associated with an increase of nearly 0.2 points in life satisfaction on a 10 -rung Cantril Ladder. ${ }^{6}$ The marginal utility of

5 To what extent is an unemployed person less satisfied than an employed person with the same personal characteristics (sex, age, status, etc.) and the same income?

6 This is somewhat smaller than the coefficient found by Stevenson/Wolfers (2008), but may be partly accounted for by the inclusion of variables referring to poverty, unemployment and education. 
additional income, however, tends to decrease and to stop at a relatively low level, at least according to earlier studies. ${ }^{7}$ For a rich person, an additional euro of wealth brings only one tenth of the life satisfaction it would give to a poor person (Layard et al. 2008). The observation that the rich are nevertheless more satisfied with their lives results from the financial security they enjoy. Income security definitely boosts life satisfaction (Freiberger Stiftung 2010: 19; Noll/Weick 2010), while income uncertainty definitely reduces it (Uhde 2010: 425). Previous unanimity with respect to a limited importance of income level has been increasingly questioned: Stevenson/Wolfers (2008), Kahneman/Deaton (2010), Sacks et al. (2010) and Boarini et al. (2012) report a significant influence of (log) income on life satisfaction. Furthermore, Inglehart/Rabier (1986) found a significant positive contribution of increased income in the preceding 12 months for Western Europe (1973-1983), while Clark et al. (2008b: 127) refers to the fact that life-income profiles with current modest increases are preferred over those with constant income. This presents an interesting contrast to the recent zero-growth discussions, claiming zero or even negative growth rates to prevent global warming, and emphasising that rich societies prefer immaterial over material wealth anyway.

The effects of relative income on life satisfaction are far more dominant than those of absolute income, as the relevant literature unanimously confirms. Most surveys, however, do not provide data, so that the empirical evidence is less dense than that of other determinants. Yet Clark et al. (2008a) provide a detailed exposition of the various attempts. Runciman (1966) has argued that people tend to compare themselves most with their nearest equals. The European Social Survey asked people: 'Whose income would you be most likely to compare your own with?' Instead of 'the rich', and somewhat surprisingly considering widely held views, the reply most often named was 'my colleagues' (Layard et al. n.d.: 62). Similarly, Layard (2005 [2011]) found that colleagues, friends and neighbours were the most frequently named reference group. Comparison is indeed an important element of life satisfaction. However, too much comparison with others reduces satisfaction. The European Social Survey asked: 'How important is it for you to compare your income with other people's incomes?' Those who answered that income comparisons were more important for them were on average less satisfied with their lives. Similar results have been found for the US (Layard et al. n.d.: 62).

Transfers and social security in particular increase the life satisfaction of the recipients (Uhde 2010). The net effect, however, is reduced by the negative side of the relativeincome effect or the loss of satisfaction of those with higher incomes. Poverty ('Not having enough money to buy food') reduces life satisfaction six times as strongly as a doubling of income (Boarini at al. 2012: 21).

The regression studies based on the surveys are unavoidably restricted in comparing the satisfaction of individuals at the same point of time. The German Socio-Economic Panel (GSOEP), however, has been tracking the same individuals over time on an annual basis since 1984. Using the Eurobarometer series since 1972 and the GSOEP since 1984, Layard et al. (n.d.: 61-62) found that differences in income explained about 1 per cent of the variance of life satisfaction in the population. In this study, no effect is left for absolute income; only relative income matters.

One further argument contributing to the discussion on the influence of absolute versus relative income posits that it is not income per se which people desire, but their position in society, which is governed by the rank in the income hierarchy and/or by commanding

$7 \quad$ Earlier studies indicate a (contemporary) income level of about $\$ 10000$ (Donovan et al. 2002: 10; Frey/Stutzer, 2002: 423; Layard 2003, lecture 1). 
specific goods and services which are inevitably in limited supply - that is, position goods (Hirsch 1977). ${ }^{8}$

The impact of inflation on life satisfaction, if investigated at all, is estimated to be relatively small and weak. Under the aspect of the violent policy debate confronting unemployment with price stability, this is astonishing and stands in strict conflict with the direct assessment to be reported in Section 4. The coefficient of the inflation term is frequently insignificant in life satisfaction regressions (Di Tella/MacCulloch 2005: 14); Alesina et al. (2001a) estimate that increasing inflation by one standard deviation (53/4 percentage points) reduces the share of the 'very satisfied' by 3 percentage points. This implies a trade-off of $13 / 4$ per cent unemployment to 1 per cent inflation, compared to the traditional misery index's 1:1 trade-off. The estimates furthermore reveal differences in ideological positions: a rise in inflation of 10 percentage points reduces the share of satisfied right-wing respondents by 7 percentage points, which is more than double the average, while left-wingers' life satisfaction suffers more from unemployment (Di Tella/MacCulloch 2005: 14, 19).

Few studies deal with the impact of the environment on life satisfaction. It is difficult to find relevant indicators for the SWB regressions, as the problem has many dimensions with a strongly diverse local impact; the environment is frequently assumed to be internalised, for example in the case of air pollution in housing prices. And, last but not least, while pollution has strongly decreased in the Western hemisphere, awareness of it has increased since the early 1970 s, so that the effects of the two tendencies on life satisfaction may to an unknown extent compensate each other. According to Rehdanz/Maddison (2005), using data on 67 countries between 1972 and 2000, cold temperatures increase life satisfaction, which implies a negative impact of global warming. Welsch (2002) found no effect of $\mathrm{SO}_{2}$ concentration on life satisfaction in a cross-section of 54 countries, while Boarini et al. (2012) detected a rather small effect of air and no effect of water quality. In Luechinger's (2009) careful study for Germany, which uses regional GSOEP data, $\mathrm{SO}_{2}$ concentration negatively affects life satisfaction to an extent of about 1 per cent to $1 \frac{1}{2}$ per cent of household income. The effect is larger for individuals concerned about the environment and, contrary to earlier assumptions, Luechinger finds air pollution incompletely capitalised in the private housing market.

Geographical mobility definitely reduces life satisfaction: the longer individuals live at the same address, the higher is their well-being (Ballas/Tranmer 2012), probably as a consequence of the better chances to build social and support networks. This is in accordance with the above-mentioned observation that single people appear to be less happy on average than married couples, and with the significant lower life satisfaction of persons born abroad (Boarini et al. 2012: 21).

Life satisfaction studies do not deal with growth explicitly, instead addressing it indirectly via unemployment. 'In the overall balance, happiness rises in booms because a one-point decrease in unemployment has at least twice as large an effect on happiness as a onepoint increase in the inflation rate. Economic stability is a crucial goal for any society, due largely to the fact of loss aversion, whereby individuals hate to lose $x$ dollars more than they love to gain $x$ dollars. But economic stability is a quite different goal from long-term economic growth. Long-term growth has much less impact on human happiness than do human relationships in all their dimensions' (Layard et al. n.d.: 66).

8 The tragedy of position goods and their contribution to life satisfaction, as well as to the income-growth race, is that everybody works hard to acquire them, but this goal is only attainable for a few and not for society as a whole. Whenever a lower income group has come to a position enabling them to obtain these goods, they lose their character as position goods, while other unavailable goods take their place. 


\subsection{Social determinants of life satisfaction}

Subjective well-being research reveals that social determinants contribute to life satisfaction in addition to individual ones. This is in accordance with a considerable body of knowledge, not least in the field of experimental economics (see Fehr/Gächter 2000, for an early survey), demonstrating that men's decisions not only rely on selfish economic motives, but also on social considerations and fairness. Life-satisfaction research enhances these perceptions, with unemployment and income distribution serving as good examples.

The social component in the relation of unemployment to life satisfaction - that is, the others' unemployment - appears to be relatively strong. 'When we total up all the wellbeing effects of a rise in the unemployment rate, the loss to the rest of the population (a large number of people) is twice as large as the loss to the unemployed themselves' (Layard et al. n.d.: 67). In addition to the psychological effect and the considerably smaller income effect, a social effect works, reducing the life satisfaction of those not affected by unemployment. A rise in unemployment by 5 percentage points - as frequently observed these days - reduces the life satisfaction of the population (whether employed or not) by 0.06 units on a four-point scale. This is equivalent to a transition of more than 10 per cent of the population to the next lower step (Di Tella et al. 2001), which is a rather strong effect. Even workers with a secure position lose satisfaction when general unemployment rises (Clark et al. 2008b).

The interpretation of the social effect of unemployment is still under discussion. Life satisfaction studies emphasise a 'fear effect' (Di Tella et al. 2006: 809): high unemployment gives a signal to the still-employed that their jobs could be endangered, and fear and stress reduce the life satisfaction of normal job holders, while government employees are not affected (Luechinger et al., 2010). At least two arguments raise some doubt about this explanation. First, surveys do not offer evidence for a widespread fear of losing one's job in normal times, nor even in 'normal' recessions, as reported below. Second, surveys provide strong evidence that workers consider their own job to be at least twice as safe as jobs in general (Tichy 2013), so that a widespread general fear is rather implausible. Justice and fairness considerations appear to provide a more plausible explanation.

Unequal income distribution lowers life satisfaction not only for the poor (Alesina et al. 2001a), as has already been shown above. ${ }^{9}$ It also affects total population, especially those with left-wing political beliefs. Unequal income distribution reduces life satisfaction in the US, and even more significantly in Europe (Alesina et al. 2001a). An increase in the Gini-coefficient of 10 percentage points - matching a transition from the Austrian to the Italian income distribution or from the Danish to the British - implies a reduction of the share of 'very satisfied' from $261 / 2$ per cent to 21 per cent and an increase of the unsatisfied from 191/2 per cent to 25 per cent. ${ }^{10}$ Corneo/Grüner (2002) distinguish a 'homo oeconomicus effect', a 'public values effect' and a 'social rivalry effect'. The first one lowers the satisfaction of those immediately affected by the unequal distribution, the second affects those rejecting inequality, and the third involves keeping an eye on one's respective own group: life satisfaction declines when reducing inequality enables a rival group to compete

9 Ninety per cent of the US population prefer a more equal distribution of wealth than today's historic high inequality (Norton/Ariely 2011).

10 One strange finding is that in the US an unequal distribution primarily reduces the satisfaction of the rich. Given the heavily unequal distribution of wealth in that country, this might point toward a guilty conscience amongst the rich, which translates into private - not policy-induced charitable action. 
for the same position goods. ${ }^{11}$ Tests using the International Social Survey programs 1992 for the USA, Canada, Australia, New Zealand, Norway, East and West Germany as well as five East European countries suggest that the selfish homo oeconomicus effect is the largest, but the public values effect is strong as well. Norwegians and Germans have the most positive attitude toward redistribution, while Americans and Australians see it in the least favourable light.

Further social determinants of life satisfaction, which have been mentioned before as they can hardly be separated from individual ones, are: social support and trust in others (Helliwell/Wang 2011), participation in society (Putnam 2001; Donovan et al. 2002; Helliwell 2002) or Social Capital (Putnam 2001; Bjørnskov 2003).

\section{POSITIVE AFFECT ('HAPPINESS’) AND ITS DETERMINANTS}

Searching for a policy goal, life satisfaction, the cognitive side of subjective well-being, is the most promising candidate. Yet a few remarks with respect to the emotional side or the affect balance may be worthwhile, as positive affect ('happiness') as a policy goal may turn out to be rather similar to a populist short-term-oriented poll-driven policy. 'Although short term emotional reports carry much less information about life circumstances than do life evaluations, they are very useful in revealing the nature and possible cause of changes in moods on an hour-by-hour or day-per-day basis' (Helliwell/Wang n.d.: 15). "Thus "happiness yesterday" ... has very different properties from life satisfaction asked on the same scale from the same respondents. The affect measure of happiness is much less correlated with major life circumstances than are the life satisfaction answers, and the effects of income are much smaller and often statistically insignificant' (ibid.: 15, emphasis added). Boarini et al. (2012: 24) carried out the same regression for both aspects of SWB - life satisfaction and positive affect ('happiness') - for 34 OECD countries and found comparable determinants. However, being 'Female'12 and being 'Afraid To Express Political Views' changed signs, and all coefficients differed substantially: 'Volunteering', 'Trust', 'Tertiary Education', 'Log Income' and 'Unemployment' have less than 40 per cent of the impact on the affect balance than they have on life satisfaction, while 'Number of Children', 'Personal Safety', 'Freedom' and 'Health' have almost twice the impact (Boarini et al. 2012: 24). The two aspects of SWB in fact measure different aspects.

The difference between life satisfaction and affect crops up clearly in the Eurobarometer surveys. In addition to the question about life satisfaction, citizens are asked: 'What do you think are the two most important issues facing you personally/our country at the moment?' (emphasis added), which is more or less the same as the inverse of positive affect. Compared to life satisfaction, rather different determinants are indeed discovered. Table 1 reveals that most Europeans were personally most concerned with inflation in spring 2013, which is found to be neither an important constituent of life satisfaction, nor a real-world

11 Examples of this are rent provisions, enabling 'lower classes' to enter 'good' living quarters, or measures that give immigrants access to good schools.

12 'Given the consistency in terms of the sign on other coefficients, this raises questions about the different gender responses to alternative measures of subjective well-being. One possibility is that women are more willing to report more extreme responses than men, which would be consistent with a higher average score on life satisfaction (with more women scoring highly overall due to the general rightward skew of the life satisfaction data distribution), but a lower affect balance (with women reporting both more positive and more negative emotions)' (Boarini et al. 2012: 22). 
Table 1 Main problems indicated by EU-respondents in spring 2013

\begin{tabular}{lccc}
\hline & \multicolumn{3}{c}{ For the: } \\
\cline { 2 - 4 } & respondent & country & EU \\
\hline Inflation & $41 \%(1)$ & $20 \%(3)$ & $13 \%(3)$ \\
Unemployment & $22 \%(2)$ & $51 \%(1)$ & $38 \%(2)$ \\
Economic situation & $18 \%(3)$ & $33 \%(2)$ & $48 \%(1)$ \\
$\ldots \ldots \ldots . . . \ldots . . . . . .$. & $\ldots \%(12)$ & $4 \%(12)$ & $3 \%(12)$ \\
\hline
\end{tabular}

Source: Eurobarometer 79 (2013).

problem at this time. ${ }^{13}$ The problem mentioned second-most frequently was unemployment, which in fact matches the results of life satisfaction research. The environment, the climate and energy belong to the least pressing problems in direct surveys. For their countries - in contrast to themselves personally - respondents consider unemployment to be the largest problem, which implies that they do not feel that they could get involved personally; unemployment is evidently considered a problem for other people, notwithstanding the fact that unemployment as such reduces life satisfaction. ${ }^{14}$ Inflation is relegated to third place in the survey's list of country problems. Surprisingly, it is perceived as a high-ranking personal problem and not so much a problem for the country even less so for the EU or the world. Climate and energy, attaining only rank 12, are in no case considered serious problems, whether personally, for the country or for the EU.

The economic determinants of the emotional-affective side of social well-being ('happiness') are exactly those dominating the public debate: inflation, unemployment and growth ('economic situation'), supporting the supposition of a poll-oriented myopic policy. As they differ from those revealed by SWB research, they do not maximise life satisfaction. Growth per se and inflation have not been found to be particularly relevant for citizens' life satisfaction.

\section{THREE LAYERS OF DETERMINANTS OF WELL-BEING AND THE POLICY CONSEQUENCES}

Given the determinants named above positive affect, 'happiness' should not be considered as a policy goal. Yet self-reported life satisfaction suffers from deficiencies as a policy goal as well. A selection bias result from the fact that persons without a fixed residence or without a telephone are inevitably excluded, and additionally problems of non response exist: Heffetz/ Rabin (2013) found that easy-to-reach respondents differ from hard-to-reach ones, so that conclusions of a survey could reverse with more attempted calls. What is more,

13 This could be a media-induced fear, triggered by the strong increase in base money. It is, however, more convincing to explain it as a reflection of stagnating real incomes: people realise that their nominal incomes increase at least slightly, but they cannot consume more, so they blame inflation for the wedge.

14 Tichy (2013) calls this general phenomenon the 'two-stage optimism gap'. People strongly tend to assess their individual situation, notably their job or their financial situation, much more positively than those of their country, and those of their country more positively than those of the EU or even the world. This mainly reflects an optimism bias, but a selection bias may also contribute. As the surveys are based on telephone interviews, they may over-represent those with jobs, particularly those with secure jobs. 
self-reported life satisfaction evidently is biased towards medium-term goals: it may underrate sustainability and trade-offs, and the government may be unable to control some of the most relevant goals. Remember that the determinants of life satisfaction are not the respondents' answers to questions in the surveys, but rather the results obtained by research, and that SWB studies search for the specific facts that make individuals more or less satisfied. These, however, need not be the determinants the individuals themselves are conscious of. They may misjudge the satisfaction resulting from their choices due to analytic errors, myopic impulses, inattention, passivity or misinformation (Stutzer/Frey 2007; Beshears 2008), they may not be aware of the (longer-term) consequences of their decisions, disregarding the consequences of their choices on macro variables and the backlash on their life satisfaction. The judgements may seemingly be objective, if aspirations affect people's cognitive well-being (Kahneman/Krueger 2006) or if the respondents form them with respect to what they consider as unchangeable reality or proper fulfilment of social expectations. ${ }^{15}$ Respondents furthermore continuously adapt their aspirations to news, thereby superimposing previous choices, and their satisfaction with material things almost inevitably wears off within 4 to 5 years (the well-known adaptation effect).

All of this points towards the necessity of accurately distinguishing three different layers of contributing factors to individual and, even more so, to social well-being:

- what individuals themselves feel makes them 'happy' (positive affect) at a particular moment, or, conversely, what they consider the most pressing immediate problems when asked directly;

- what turns out to have contributed to individuals' life satisfaction, as discovered by life satisfaction research, asking how satisfied people are with their lives on the whole nowadays, covering the more medium-term aspects; and

- what is sustainable in the long run, given the unintended consequences of pursuing intended and unintended individual goals, as stated in answering direct questions or worked out by SWB research.

The differentiation clearly reveals the most important result, that a policy directly based on the determinants of positive affect (opinion polls) would turn out to be myopic and unsuitable to bringing about life satisfaction. But even a policy attempting to maximise people's (revealed actual) life satisfaction could be prone to reducing life satisfaction in the long run, as such a policy would eventually neglect the externalities reducing life satisfaction, or at least the life satisfaction of the next generation. This is not to deny that the choice of the policy goal life satisfaction would have three advantages. First, it would set straight the rank and weight policy that should be assigned to the different goals in order to be more in line with citizens' priorities. Second, and at least as important, policy would be less myopic than the actual mixture of opaque decisions of politicians, poll orientation and the selfserving pressures of lobbies. Third, the results of life-satisfaction research clearly advise policy that social goals and a fair distribution of income and wealth can even contribute to the life satisfaction of those not directly profiting. They reveal, moreover, that policy seriously underestimates the relevance of institutional goals (for example, health, freedom and social capital).

Thus, a life-satisfaction-oriented policy could improve welfare in the short to medium term. As for the longer-term goals, life satisfaction (and the more positive affect) as the dominating goal of policy would turn out to be a problematic short-cut. It would conceal

15 See the gender-job-satisfaction paradox as an example, which shows that the objectively disadvantaged labour market group of female workers possesses a higher subjectively assessed level of job satisfaction as compared to male workers (Clarke 1997; Kaiser 2007). 
what should dominate the substance of a serious policy debate: the compatibility of shortterm and long-term goals, the distribution of burdens among generations, and the ability to cope with diverse trade-offs. While incompatibilities may be less serious in the short and medium run, grave problems can arise in the long run, mainly due to sustainability issues. A social dilemma exists in the form of serious tensions between various elements of life satisfaction, including those elements that are not aimed at the environment but have a direct impact on it in the long term. And the environment is not the only aspect of sustainability, as it also encompasses the important 'sustainabilities' of full employment, secure and humane jobs, adequate work-life balance, pensions ${ }^{16}$ and health systems, government finance and the inanity of the rat-race, relative to income and position goods. All of these problems have trade-offs which are considered relevant by many citizens, but which do not pertain to the life satisfaction of the majority. They tend to consider it a problem of technology or policy, utilising instruments, however, that do not disturb their specific life style. The long-term aspects seem far from capable of inducing the majority of citizens to reassess let alone change their aspirations, attitudes and behaviour. ${ }^{17}$

As for policy's limited potential to control the determinants of SWB, Section 3 demonstrated at length that the individual determinants of life satisfaction are at least as important as the economic and institutional ones, with unemployment presenting an important exception. Even important economic determinants, such as relative income or leisure, are largely outside governments' control. In consequence, designating life satisfaction as the dominant goal of policy implies choosing a goal whose determinants can only be partially controlled. Thus, the decision to choose life satisfaction as the dominant policy goal would be self-defeating. Citizens would quickly discover that policy cannot live up to its promise, and their faith in policy, which is already deplorably low, ${ }^{18}$ would decrease even further. Self-reported life satisfaction, defined properly, can be an important element in a vector of policy goals. But it cannot relieve politicians from constantly assessing trade-offs and sustainability, and searching for compromises among the conflicting ideological positions. Weber's (1919: 66, my translation) conclusion that 'politics is a strong and slow boring of hard boards' still holds true; putative short-cuts tend to contribute to disorientation.

\section{REFERENCES}

Alesina, A., Di Tella, R., MacCulloch, R. (2001a): Inequality and happiness: are Europeans and Americans different?, NBER Working Paper 8198.

16 The literature on pension reforms almost exclusively suggests an increase in labour input as a solution, either through a longer life working period or higher participation, both of which imply higher production and, consequently, higher consumption (see, for example, Börsch-Supan 2013), clearly contradicting the sustainability goals.

17 Citizens frequently find consolation in persuading themselves that they alone cannot change the disaster, or - as the Eurobarometer reveals - by considering themselves not personally involved. In consequence, they complain about emissions, while marketing and buying high-emission cars, fighting violently against higher gasoline prices and striving for traffic-generating and energy-wasting single family houses. They fear old-age, but are neither prepared to work longer nor to agree to higher contributions. They lament over too-high government debt, but reject a curtailing of public expenditure. As an excuse, they frequently cling to 'technical' solutions (which are supposed to work 'automatically' and do not afford any personal action or renunciation), even if experience has shown that no single technical solution has ever sufficed to solve environmental problems.

18 Only 27 per cent of EU respondents trusted their government (Eurobarometer 78 2012). 
Alesina, A., Glaeser, E.L., Sacerdote, B. (2001b): Why doesn't the United States have a European style welfare state?, in: Brooking Papers on Economic Activity, Fall, 187-277.

Alesina, A., Glaeser, E.L., Sacerdote, B. (2006): Work and leisure in the United States and Europe: why so different?, in: NBER Macroeconomics Annual 2005, 1-99.

Argyle, M. (1987): The Psychology of Happiness, London: Methuen.

Ballas, D., Tranmer, M. (2012): Happy people or happy places? A multilevel modelling approach to the analysis of happiness and well-being, in: International Regional Science Review, 35(1), 70-102.

Becchetti, L., Castriota, S., Bedoya, D.A.L. (2007): Climate, happiness and the Kyoto protocol: someone does not like it hot, Centre for Economic and International Studies (CEIS) Working Paper 247.

Beshears, J., Choi, J.J., Laibson, D., Madrian, B.C. (2008): How are preferences revealed? in: Journal of Public Economics, 92, 1787-1794.

Bjørnskov, Ch. (2003): The happy few: cross-country evidence on social capital and life satisfaction, in: Kyklos, 56, 3-16.

Blanchflower, D.G., Oswald, A.J. (2004): Well-being over time in Britain and the USA, in: Journal of Public Economics, 88(7-8), 1359-1386 (NBER Working Paper 7487).

Blinder, A.S. (ed.) (1990): Paying for Productivity: A Look at the Evidence, Washington, DC: The Brookings Institution.

Boarini, R., Comola, M., Smith, C., Manchin, R., de Keulenaer, F. (2012): What makes for a better life? The determinants of subjective well-being in OECD countries - evidence from the Gallup World Poll, OECD Statistics Working Papers, 2012/03, URL: http://dx.doi.org/10.1787/ 5k9b9ltjm937-en.

Börsch-Supan, A. (2013): Ageing, labour markets and well-being, in: Empirica, 40(3), 397-407.

Clark, A.E. (1997): Job satisfaction and gender: why are women so happy at work?, in: Labour Economics, 4(4), 341-372.

Clark, A.E. (2001): Unemployment as a social norm: psychological evidence from panel data, in: Journal of Labour Economics, 21(2), 323-351.

Clark, A., Frijters, P., Shields, M. (2008a): Relative income, happiness, and utility: an explanation for the Easterlin paradox and other puzzles, in: Journal of Economic Literature, 46(1), 95-144.

Clark, A., Knabe, A., Rätzel, S. (2008b): Boon or bane? Others' unemployment, well-being and job insecurity, CESifo Working Paper 2501.

Clark, A.E., Oswald, A.J. (1994): Unhappiness and unemployment, in: Economic Journal, 104(424), 648-659.

Clark, A.E., Oswald, A.J. (2002): Well-being in panels, Mimeo, University of Warwick.

Clark, A.E., Senik, C. (2011): Is happiness different from flourishing? Cross-country evidence from the ESS, Working Paper 2011-04, Paris: School of Economics.

Corneo, G., Grüner, H.P. (2002): Individual preferences for political redistribution, in: Journal of Public Economics, 83(1), 83-107, URL: http://www.elsevier.com/locate/inca/505578.

Deaton, A. (2008): Income, health, and well-being around the world: evidence from the Gallup poll, in: Journal of Economic Perspectives, 22(2), 53-72.

Demir, M. (2013): Introduction to relationships and happiness, in: David, S.A., Boniwell, I., Conley Ayers, A. (eds), Oxford Handbook of Happiness, Oxford: Oxford University Press, 817-818.

Diener, E., Chan, M. (2011): Happy people live longer: subjective well-being contributes to health and longevity, in: Applied Psychology: Health and Well-being, March, 1-43.

Diener, E., Suh, E.M., Lucas, R.E., Smith, H. (1999): Subjective well being; three decades of progress, in: Psychological Bulletin, 125(2), 276-303.

Di Tella, R., MacCulloch, R. (2005): Partisan social happiness, in: Review of Economic Studies, 72, 367-393.

Di Tella, R., MacCulloch, R.J., Oswald, A.J. (2001): Preferences over inflation and unemployment: evidence from surveys of happiness, in: American Economic Review, 91(1), 335-341.

Di Tella, R., MacCulloch, R.J., Oswald, A. (2006): The macroeconomics of happiness, in: Review of Economics and Statistics, 85(4), 809-827.

Donovan, N., Halpern, D., Sargeant, R. (2002): Life satisfaction: the state of knowledge and implications for government, Strategy Unit, UK Government, London. 
Eurobarometer 78 (2012): Public Opinion in the European Union, First Results, Brussels: European Commission.

Eurobarometer 79 (2013): Public Opinion in the European Union, First Results, Brussels: European Commission.

Fehr, E., Gächter, S. (2000): Fairness and retaliation: the economics of reciprocity, in: Journal of Economic Perspectives, 14(3), 159-181.

Flora, C. (2009): The pursuit of happiness, URL: http://www.psychologytoday.com/articles/ 200812/the-pursuit-happiness.

Freiberger Stiftung (2010): Zufrieden trotz sinkenden materiellen Wohlstands, Amerang.

Frey, B.S., Stutzer, A. (2000): Happiness, economy and institutions, in: Economic Journal, 110, 918-938.

Frey, B.S., Stutzer, A. (2002): What can economists learn from happiness research?, in: Journal of Economic Literature, 40(2), 402-435.

Frey, B.S., Stutzer, A. (2008): Stress that doesn't pay: the commuting paradox, in: Scandinavian Journal of Economics, 110(2), 339-366.

Gerlach, K., Stephan, G. (1996): A paper on unhappiness and unemployment in Germany, in: Economic Letters, 52(3), 325-330.

Heffetz, O., Rabin, M. (2013): Conclusions regarding cross-group differences in happiness depend on difficulty of reaching respondents, in: American Economic Review, 103(7), 3001-3021.

Helliwell, J.F. (2002): How's life? Combining individual and national variables to explain subjective well-being, NBER Working Paper 9065.

Helliwell, J.F., Wang, S. (2011): Weekends and subjective well-being, NBER Working Paper 17180.

Helliwell, J.F., Wang, S. (n.d.): The state of world happiness, in: Helliwell, J.F., Layard, R., Sachs, J. (eds), World Happiness Report, 10-57.

Hirsch, F. (1977): Social Limits to Growth, London/Henley: Routledge \& Kegan Paul.

Inglehart, R., Klingemann, H.-D. (2000): Genes, culture, democracy, and happiness, in: Diener, E., Suh, E.M. (eds), Culture and Subjective Well-Being, Cambridge, MA: MIT Press, 165-183.

Inglehart, R., Rabier, J.-J. (1986): Aspirations adapt to situations - but why are the Belgians so much happier than the French? A cross-cultural analysis of the subjective quality of life, in: Andrews, F.M. (ed.), Research in the Quality of Life, Ann Arbor: University of Michigan Press, 1-49.

Kahneman, D., Deaton, A. (2010): High income improves evaluation of life but not emotional wellbeing, URL: http://www.pnas.org/content/107/38/16489.long.

Kahneman, D., Krueger, A.B. (2006): Developments in the measurement of subjective well-being, in: Journal of Economic Perspectives, 20(1), 19-20.

Kaiser, L.C. (2007): Gender-job satisfaction differences in Europe, in: International Journal of Manpower, 28(1), 75-94.

Kasser, T., Ryan, R.M. (2001): Be careful what you wish for: optimal functioning and the relative attainment of intrinsic and extrinsic goals, in: Schmuck, P., Sheldon, K.M. (eds), Life Goals and Well-Being: Towards a Positive Psychology of Human Strifing, Kirkland, WA: Hogrefe and Huber, 116-131.

Kruse, D., Blasi, J. (1995): Employee ownership, employee attitudes, and firm performance, NBER Working Paper 5277.

Layard, R. (2003): Happiness: has social science a clue? Lionel Robbins Memorial Lecture 2002, URL: http://cep.lse.ac.uk/events/lectures/layard/RL050303.pdf.

Layard, R. (2005 [2011]): Happiness: Lessons from a New Science, London: Penguin.

Layard, R., Clark, A., Senik, C. (n.d.): The causes of happiness and misery, in: Helliwell, J.F., Layard, R., Sachs, J. (eds), World Happiness Report, 58-89.

Layard, R., Mayraz, G., Nickell, S. (2008): The marginal utility of income, in: Journal of Public Economics, 92(8-9), 1846-1857.

Lucas, R.E., Clark, A.E., Georgellis, Y., Diener, E. (2004): Unemployment alters the set-point for life satisfaction, in: Psychological Science, 15, 8-13.

Luechinger, S. (2009): Valuing air quality using the life satisfaction approach, in: Economic Journal, 119(March), 482-515. 
Luechinger, S., Meier, S., Stutzer, A. (2010): Why does unemployment hurt the employed? Evidence from the life-satisfaction gap between private and public sector, in: Journal of Human Resources, 45(4), 998-1045.

Mulgan, G. (2013): Well-being and public policy, in: David, S.A., Boniwell, I., Conley Ayers, A. (eds), Oxford Handbook of Happiness, Oxford: Oxford University Press, 517-532.

Noll, H., Weick, S. (2010): Subjective well-being in Germany: evolutions, determinants and policy implications, in: Greve, B. (ed.), Happiness and Social Policy in Europe, Cheltenham, UK and Northampton, MA: Edward Elgar, 70-88.

Norton, M.I., Ariely, D. (2011): Building a better America - one wealth quintile at a time, in: Perspectives on Psychological Science, 6, 9-12.

OECD (1995): Employment Outlook, Paris: OECD.

Oswald, A.J. (1997): Happiness and economic performance, in: Economic Journal, 107, 1815-1831.

Oswald, A.J., Powdthavee, N. (2005): Does happiness adapt? A longitudinal study of disability with implications for economists and judges, Department of Economics, University of Warwick.

Prescott, E.C. (2004): Why do Americans work so much more than Europeans?, in: Federal Reserve Bank of Minneapolis Quarterly Review, 28(1), 2-13.

Putnam, R.D. (2001): Bowling Alone: The Collapse and Revival of American Community, New York: Simon \& Schuster.

Rehdanz, K., Maddison, D. (2005): Climate and happiness, in: Ecological Economics, 52(1), 111-125.

Runciman, W.G. (1966): Relative Deprivation and Social Justice, Henley, UK: Routledge.

Sachs, J. (n.d.): Introduction, in: Helliwell, J.F., Layard, R., Sachs, J. (eds), World Happiness Report, 3-9.

Sacks, D.W., Stevenson, B., Wolfers, J. (2010): Subjective well-being, income, economic development and growth, NBER Working Paper 16441.

Stevenson, D., Wolfers, J. (2008): Economic growth and subjective well-being: reassessing the Easterlin Paradox, in: Brookings Papers on Economic Activity, Spring, 1-87.

Stutzer, A., Frey, B.S. (2007): What happiness research can tell as about self-control problems and utility misprediction, in: Frey, B.S., Stutzer, A. (eds), Economics and Psychology: A New Promising Cross-Disciplinary Field, Cambridge, MA: MIT Press, 169-195.

Tichy, G. (2013): Finanzkrise und Lebenszufriedenheit, in: Wirtschaft und Gesellschaft, 39(3), 323-342.

Uhde, N. (2010): Soziale Sicherheit und Lebenszufriedenheit: Empirische Ergebnisse, in: Perspektiven der Wirtschaftspolitik, 11(4), 407-439.

Veenhofen, R. (2000): Freedom and happiness in forty-four nations, in: Diener, E., Suh, E.M. (eds), Culture and Subjective Well-Being, Cambridge, UK: Cambridge University Press, 257-288.

Weber, M. (1919): Politik als Beruf, München und Leipzig: Duncker \& Humblot, 66.

Welsch, H. (2002): Preferences over prosperity and pollution: environmental valuation based on happiness surveys, in: Kyklos, 55(4), 473-494.

Wulfgramm, M. (2011): Can activating labour market policy offset the detrimental life satisfaction effect of unemployment?, in: Socio-Economic Review, 9, 477-501, doi:10.1093/ser/mwr006. 